\title{
O cinema autorreferencial de Chantal Akerman como ato de teoria do deslugar
}

\author{
Natália Lago Adams \\ Mestranda; Universidade Tuiuti do Paraná, UTP, Curitiba, PR, Brasil. \\ natalialagoadams@gmail.com.
}

\section{Sandra Fischer}

Doutora; Universidade Tuiuti do Paraná, UTP, Curitiba, PR, Brasil. sandrafischer@uol.com.

\section{Resumo}

O artigo observa a condição de deslugar focando o olhar críticoanalítico prioritariamente no universo do cineasta, considerando que na pós-modernidade e contemporaneidade proliferam as produções que se fazem território autorreferencial do criador. Parece ser o caso de Chantal Akerman, cuja filmografia apresenta indícios do 'eu' no âmbito ficcional e no documental, permitindo identificar, na dimensão do que se entende como deslugar, o predomínio de um peculiar, oscilante pertencimento/não-pertencimento manifesto em constantes deslocamentos e perambulações. Neste sentido, à luz das reflexões acerca do filme como ato teórico propostas por Jacques Aumont, o estudo parte do método de análise comparativa para observar excertos dos filmes Je, $t u$, il, elle (1974), News from home (1976) e Les rendez-vous d'Anna (1978) a fim de examinar o pensamento autobiográfico que sustenta as narrativas da diretora belga - buscando confirmar a hipótese de que as labilidades espaciais e psicológicas consistem no traço distintivo de seu trabalho. $O$ objetivo do estudo é investigar se e como tal característica é transversal na obra da diretora belga, ali impregnando a inteligência criadora de modo a afetar diretamente as articulações poéticas e sensíveis. Ao comparar as declarações de Akerman no documentário I don't belong anywhere (2015) com as diegeses do corpus em questão, os resultados obtidos indicam ser possível, por ora, confirmar a manifestação a condição de deslugar tanto nas personagens, quanto em quem as criou.

\section{Palavras-chave}

Chantal Akerman. Deslugar. Autorreferência. Ato teórico. 


\section{Introdução}

Considerando que a teoria é da ordem da abstração, como poderia, então, um filme adquirir caráter teórico? Se o que define uma teoria é seu caráter coerente e explicativo, plenamente cumpridos pela palavra, a imagem (e, por consequência, o cinema) encontra uma série de limitações para sê-la¹. Motivado por essa problematização, Jacques Aumont (2008) reflete sobre a (im)possibilidade de imagens fazerem-se veículos ou mesmo locais de pensamento direto, sem intermediação. É alinhado, de certo modo, com a proposição de Jean Louis Schefer $\left(1980^{2}, 1997^{3}\right.$ apud AUMONT, 2008) de que a imagem como forma de pensamento aproxima-se ao "pensamento pré-verbal", fazendo-se testemunha do exercício de pensar, que o autor propõe: filmes apenas podem estar ligados à teorização (de modo que não se constituem como teoria, mas sim ato desta) em um sentido amplo:

Inicialmente, no sentido do particular em oposição ao geral: só com dificuldade e de maneira insuficiente pode um filme tratar de uma grande questão teórica (o capitalismo e o socialismo, a propagação das ideias ou o lugar do espectador), mas ele pode restringir sua ambição. [...] Segunda possibilidade: um filme pode particularizar sua reflexão ao restringir não mais o objeto da pesquisa, mas as suas condições: ao se tornar claramente uma experiência. [...] Terceira resposta: um filme é um ato, todo filme é um ato - mas um ato poético. É na qualidade de ato de invenção, ato de pensamento e de criação que, em última análise, um filme pode evocar, imitar ou chegar perto da teoria [...] (AUMONT, 2008, p. 30-31).

Interessa, aqui, a terceira possibilidade. Tomando-a como ponto de partida para observar a filmografia de Chantal Akerman, este estudo mira para além das câmeras, para o suposto momento da criação. Surge, aí, uma série de hipóteses e questões cujas respostas (provisórias, que sejam) serão buscadas nas próximas páginas: que pensamento orientaria, tendencialmente, a inteligência criadora dos filmes da diretora belga e/ou o seu enunciado discursivo? De que modo esse pensamento atravessaria a filmografia da cineasta, afetando

\footnotetext{
1 “[...] para ser capaz de especular sobre um problema geral (filosófico, se preferirmos, mas não necessariamente), um filme deve munir-se dos meios formais apropriados; ele deve até mesmo inventá-los, e pode-se afirmar que não existe especulação em um filme que não inova em seu dispositivo ou em sua forma [...]. Mesmo o mais rapsódico dos filmes, o mais poético e o mais singular, se tem alguma pretensão a teorizar, deverá encontrar uma forma de coerência. [...]. Evidentemente, o filme é aqui sempre limitado pela natureza metafórica e indireta de sua reflexão teórica [...]" (AUMONT, 2008, p. 26-30).

2 SCHEFER, Jean Louis. L'Homme ordinaire du cinéma. Cahiers du cinéma, Paris: Gallimard, 1980.

3 SCHEFER, Jean Louis. Du monde et du mouvement des images. Paris: Gallimard, 1997.
} 
sua dimensão sensível? Que enunciado as imagens traduziriam, ou, mais precisamente, haveria nelas um ato de teoria?

No título de seu documentário I don't belong anywhere: the cinema of Chantal Akerman (2015), Marianne Lambert traduz o que se faz latente nas imagens: em anos de idas e vindas entre cidades como Bruxelas, Paris, Nova Iorque e Tel Aviv, Akerman nunca viveu lá ou acolá, mas sim em todos e nenhum desses lugares, simultaneamente. Onde quer que estivesse, o que chamava de casa parecia estar do outro lado. Teria experimentado aí, muito provavelmente, a julgar pelas imagens que apresenta, uma suspensão de seu próprio estar que lhe lançou em uma condição de nem/nem, característica da situação de deslugar4: nem dentro e nem fora. Atrelada ao permanente desconforto, ao estranhamento, a posição de deslugar configura um descompasso entre um dado espaço situacional e seu ocupante. Enquanto a noção de não lugar relaciona-se ao estar de passagem, à provisoriedade e ao não pertencer, e a de entre-lugar contempla o pertencer a dois ou mais lugares, o estar posicionado entre duas ou mais situações, a ideia de deslugar implica um estar desacertado, des-encaixado: um alojamento parcial, um descompasso entre um espaço situacional e seu ocupante.

A proposta conceitual do termo, aplicada a personagens de filmes ficcionais, surge atrelada à condição de figuras solitárias, perambulantes e, em maior ou menor grau, atravessadas por uma espécie de angústia, um desajuste somatizado; personagens colocadas, no espaço fílmico, em situação de deslugar - perspectiva a partir da qual se configura certa estética peculiar que se expande, principalmente no cinema que trata de cotidianos e interioridades, em poéticas do deslugar. Na medida em que Akerman se faz, frequentemente objeto de seu oeuvre, levanta-se aqui a possibilidade de expandir a ideia de deslugar para além do universo diegético ${ }^{5}$, olhando para o ato de pensamento e criação de que fala Aumont (2008).

\footnotetext{
4 A ideia de deslugar, conceito ainda em desenvolvimento, parte dos estudos comunicacionais e psicanalíticos de Sandra Fischer (2010; 2014): trata-se de uma situação topológica que apresenta tipologia, estruturação e configuração peculiares; em termos resumidos, seria uma posição: (1) de ordem basicamente psíquica, intelectual, emocional; (2) definida pelo não estar dentro e o não estar fora, simultaneamente, de uma dada conjuntura, de uma determinada condição, ou seja: o estar em deslugar, situação de caráter marcado pela afirmação e/ou reconfiguração de valores que permeiam as camadas da intimidade e da interioridade, tanto no âmbito do social quanto naquilo que tange à esfera do pessoal/individual, define-se, estruturalmente, pelo nem/nem (FISCHER, 2014, 2010). Em certa extensão, o deslugar funciona como uma espécie de sintoma - na medida em que o sintoma, emergência do Real (termo aqui empregado na perspectiva dos estudos lacanianos), sinaliza que há algo "fora de lugar", fora do campo simbólico (LACAN, 1978).

5 Não é intenção do estudo meramente apontar a condição de deslugar na pessoa da cineasta - nosso interesse recai sobre suas obras. Encontrar indícios de tal condição em Akerman é, julga-se, relevante justamente por nos permitir, em via de mão dupla, uma compreensão aprofundada de seu oeuvre, bem como o aprofundamento do próprio conceito em desenvolvimento. Do mesmo modo, não é também objetivo desta pesquisa apenas verificar se há uma autoinscrição da
} 
Para elucidar essa nova mirada, o corpus deste artigo é composto por três filmes roteirizados e dirigidos pela cineasta em pauta, selecionados em razão de seus diferentes modos de representação: Je, tu, il, elle (1974), News from home (1976) e Les rendez-vous d'Anna (1978). No primeiro deles, de caráter ficcional, Je, tu, il, elle, Akerman interpreta uma personagem sobre a qual pouco é revelado, abrindo brecha para que ela possa ser vista como uma extensão da própria diretora e, aí, atriz: a narrativa, conduzida em primeira pessoa, aliada a outros elementos da construção fílmica, dá margem a essa visada, como o nomadismo, a homossexualidade e a carta que narra (a qual indica uma escrita de si, visto que fora redigida por Akerman anos antes de conceber o filme). Já o documentário News from home consiste em cenas das ruas de Nova Iorque, captadas por Akerman que ali vivia então, somadas à narração em off, na voz da própria cineasta, de cartas que ela recebera de sua mãe após mudar-se de Bruxelas para a cidade norte-americana. Por sua vez, Les rendezvous d'Anna, também de ordem ficcional, acompanha a trajetória de uma protagonista que tem muito em comum com Akerman - no documentário de Lambert, a própria atriz que a interpreta, Aurore Clément, declara que a personagem de fato é uma persona da diretora.

Há outras obras dirigidas e estreladas por Akerman que também se revelam marcadas pela subjetividade e autorreferência: em Saute ma ville, seu curta-metragem de estreia, ela protagoniza o papel de uma jovem sem identidade definida; também aparece em outra película de curta duração no início de sua carreira, La chambre 2, na qual o olhar da câmera varre, em movimentos de $360^{\circ}$, o próprio quarto da cineasta que, por vezes, é flagrada na cama; Là-bas, por sua vez, consiste em cenas cotidianas em Tel Aviv, captadas pela cineasta a partir das dependências de seu apartamento provisório - que se apresenta quase como um hotel - , somadas à narração em off de memórias e divagações sobre sua vida pessoal; finalmente, na obra derradeira, No home movie, ela revela intimidades de sua relação com a mãe, Natalia Akerman. Note-se ainda que Akerman chegou mesmo a dirigir um documentário autobiográfico voltado para sua carreira, Chantal Akerman par Chantal Akerman. Não obstante sua relevância, esses filmes não são tratados neste trabalho: priorizou-se na seleção do corpus obras em que os elementos que aqui se buscam se fazem mais explicitamente identificáveis.

Os três longas-metragens selecionados voltam-se às miudezas do cotidiano, a eventos banais e, por vezes, enfadonhos - redigir uma carta, caminhar pela cidade, andar de

diretora belga em suas películas - demasiados trabalhos já o fizeram -, mas sim promover essa análise a fim de buscar nela o deslugar e, então, pensar no corpus como ato teórico. 
metrô ou trem -, preenchendo imagens que se revelam quase documentais, tal a proximidade do que, em linhas gerais, entende-se como realidade. Esse fluxo de rotina, no entanto, é embargado por uma perturbadora condição de inadequação. Cada uma a seu modo, as películas evidenciam um sentimento de, ao mesmo tempo, ser e não ser, estar presente e distante. As personagens ocupam fisicamente o lugar que lhes é designado, mas psicologicamente não pertencem a ele; quando se deslocam para um novo sítio, nele também não se encaixam: se o lar causa estranhamento, por outro lado espaço algum se revela acolhedor. Essa des-acomodação é, diga-se, a base da definição que vem sendo proposta para o termo deslugar.

Postas estas questões, este trabalho parte da premissa inicial do que seria a condição de deslugar para, então, analisar o corpus do estudo. A metodologia para tal consiste em, após descrever os excertos fílmicos atinentes à proposta da pesquisa, observar a construção da narrativa, os procedimentos estéticos adotados e os efeitos de sentido ali encontráveis, buscando identificar os indícios da figura do eu ali em questão para verificar se haveria, no contexto em análise, a peculiar desacomodação que caracteriza o estar no mundo do sujeito em situação de deslugar. Finalmente, entendendo um ato de teoria como concretização figurativa de um enunciado de ordem abstrata, conclui-se que os filmes analisados podem ser considerados como tal partindo de três confirmações: as revelações de não pertencimento de Chantal Akerman em I don't belong anywhere; a contaminação de suas películas, sejam elas documentais ou não, por indícios de si; a presença diegética das marcas de deslugar que, assim, faz-se enunciado imagético.

\section{Eu não pertenço a lugar algum: sobre o deslugar}

A concepção de deslugar leva em consideração dois outros conceitos: o de lugares antropológicos e de não-lugares. Ambos foram propostos e elucidados por Marc Augé (2010) ao delinear as relações rotineiras estabelecidas entre os indivíduos "sobremodernos" e os espaços em que habitam e transitam. Grosso modo, a primeira categoria abrange locais em que se dão vivências relacionais, históricas e identitárias, enquanto a segunda se volta para aqueles da ordem do anonimato e da passagem, nos quais os compartilhamentos são efêmeros e as trocas, superficiais, se não inexistentes. A ideia de deslugar relaciona-se com tais noções na medida em que, posto de maneira simples, o 
indivíduo em situação de deslugar efetivamente não pertence desde sempre ou deixa de pertencer ao seu lugar, dado ou conquistado, e de nele estabelecer-se, para colocar-se em estado de permanente alternância entre inquietude mortificante e apatia paralisante, em persistente movimentação interior de dúvida, questionamento, ansiedade e apreensão.

Neste artigo, acrescenta-se à proposição do conceito de deslugar, cuja proposta original preconiza ser esse um estado, em princípio, de natureza exclusivamente psíquicointelecto-emocional6, a ideia de que essa espécie de trânsito constante por entre a dinamicidade e a estaticidade pode fazer com que o sujeito, eventualmente, passe a habitar fisicamente - e não apenas psicologicamente - instâncias concernentes aos ditos nãolugares. Esse habitar não acontece, no entanto, de forma acomodada e confortável, mas sim provisória e desconcertante. Instala-se, na pseudo-ocupação desses sítios, a situação típica do deslugar, caracterizada pelo nem/nem (nem cá e nem acolá): uma posição suspensa, decorrente do desacordo do ser com o espaço onde está, a qual resulta em uma tensão permanente, uma angústia e melancolia de não se encontrar.

No cinema, o que se tem entendido como deslugar tem vindo da observação de filmes ${ }^{7}$ marcados por imagens de cotidianos contaminados por esses estranhamentos e não pertencimentos, nos quais a coreografia do trivial, pragmática, se vê perturbada pelo surgimento de um desconforto psicológico. No plano diegético, os deveres cristalizados da rotina já não são mais - se é que alguma vez foram - desempenhados com naturalidade; no plano formal, cria-se um jogo imagético pautado pela alternância entre movimento e estagnação, silêncio e ruído (FISCHER, 2010). Formula-se, aí, uma estética particular, de ambiguidades, que nos permite observar o indescritível, a sensação paradoxal de estar em ausência, ser em negação - pois o cinema de cotidiano marcado pelo deslugar é aquele que revela, sutilmente, a fissura, o furo, o buraco: a presença da falta, encontrada pelo olhar minucioso lançado às lacunas próprias das tramas que tecem a vida social, que carece, entre seus fios, da familiaridade, do reconhecimento de si mesmo, da pertença. Falham ou rarefazem-se os sentimentos de acolhimento e preenchimento, a sensação de estar tudo em seu devido lugar.

\footnotetext{
6 “Bem diversa das noções topológicas de entrelugar e não-lugar é, parece-me, a tipologia, a estruturação e a configuração da noção de deslugar [...]. Características da contemporaneidade e de natureza física ou virtual, as duas primeiras podem, penso, ser transportadas para o âmbito psíquico-intelecto-emocional das relações humanas em seus desdobramentos sócioafetivo-amorosos e examinadas a partir dessa perspectiva. Já o deslugar, [...] seria de natureza exclusivamente psíquicointelecto-emocional; e, não obstante me pareça um fenômeno preponderantemente característico da contemporaneidade, seria atemporal." (FISCHER, 2010, p. 147, grifo nosso).

7 Em estudos anteriores dedicados ao delineamento do conceito de deslugar, Fischer (2010; 2014) identificou tal condição em filmes como Pai e filha, Não por acaso, O palhaço e Somewhere.
} 
3 Je, tu, il, elle

Dos 90 minutos de duração de $J e, t u$, il, elle, os primeiros 29 são preenchidos por imagens de Akerman interpretando uma personagem isolada no interior de um pequeno quarto; sua voz em off, que narra em primeira pessoa, revela o texto de uma carta que vai sendo por ela escrita. Não há indícios de quem seja o destinatário, tampouco informações sobre a remetente, exceto por seu nome, Julie. As palavras da carta fornecem a descrição mais ou menos precisa de gestos que nós, espectadores, podemos ver na tela, intercalados com declarações que exteriorizam o que nos foge aos olhos: os pensamentos de uma jovem mulher à deriva.

Dona de uma mente inquieta, porém fisicamente paralisada, ela se mostra angustiada. Parecendo não caber no cômodo diminuto e estar pouco à vontade consigo mesma, retira todos os móveis do ambiente, exceto por um colchão; desnuda-se e assim permanece por dias, apesar do frio. Suas ações limitam-se a deitar-se no chão ou sobre o colchão, sentar-se encurvada nos cantos, ingerir açúcar de mamona puro e escrever a carta que narra. Em dado momento, a personagem revela estar ali há 28 dias, o que parece tempo suficiente para que ao menos começasse a se acomodar e de fato apropriar-se do lugar, mas ela não o faz: por volta da metade do filme, decide partir. Para onde? Não parece saber.

Assim começa a segunda parte da metragem: Julie estacada à beira da estrada pedindo carona. Sobe no caminhão de um homem e segue viagem com ele, passando por diversos bares e cruzando com rostos de pessoas igualmente desconhecidas. Entre cervejas e cigarros, a narração de seus pensamentos nos revela que a jovem se sente atraída pelo motorista; com o veículo em movimento, põe-se a masturbá-lo para, em seguida, ouvi-lo contar sobre a esposa, o casal de filhos, as jovens mulheres que acolhe no caminhão e com as quais se relaciona casualmente.

Disso, partimos para uma terceira parte, os dez últimos minutos de filme. A personagem toca a campainha da residência de alguém e se identifica dizendo "Sou eu." (AKERMAN, 1974), denotando intimidade com a pessoa que se encontra do outro lado do interfone e lhe faculta a entrada, abrindo a porta ao reconhecer-lhe a voz. Sobe ao apartamento e lá depara com uma mulher, que pouco tempo depois informa a Julie que não deseja sua permanência ali. Ainda assim, alimenta a jovem e, enquanto estão à mesa, trocam 
carícias que culminam na cama. A mulher diz a Julie que ela deve ir embora no dia seguinte. Acompanhamos, então, minutos ininterruptos da relação sexual entre as duas que, por fim, passam a noite juntas. Ao despertar, Julie parte deixando a amante ainda adormecida. Novamente, não sabemos para onde. Dessa vez, sucede a tela preta que registra o fim da película.

A primeira inscrição de Akerman no filme é sua própria imagem, ao passo em que a construção de uma identidade para Julie é quase inexistente: apesar de dar nome à personagem, a cineasta não fornece um sobrenome ou um histórico (apenas vestígios deste), tampouco aprofunda seus trejeitos. Neste sentido, o contraste entre criadora e criação provoca uma fissura que torna mais evidente a identidade da primeira, como se tratasse muito mais de uma auto-imagem de Akerman do que de uma personagem. A subjetividade é reforçada por meio das cartas escritas e narradas na diegese. A carta, para Michel Foucault (2006), associa-se à escrita de si, estabelecendo uma relação atenta com si mesmo; essa relação se intensifica se levarmos em consideração que, conforme relata Akerman em I don't belong anywhere, o texto narrado fora escrito por ela em Paris, aos 18 anos, em lugar de ter sido concebido exclusivamente como parte do roteiro. Assim, o que ouvimos são palavras de Akerman, que na situação fílmica são emprestadas a Julie.

O que, no entanto, talvez constitua com mais clareza esse encontro entre criadora e criação é o nomadismo: depois de começar sua carreira no cinema, Akerman morou em cidades de diferentes países sem, no entanto, fixar residência em uma só - pelo menos, não por longos períodos - ou deixar para trás seu lar anterior ao encontrar o próximo. Enquanto isso, Julie indica nas primeiras palavras que profere no filme que acaba de se mudar para o quarto que vemos - "E foi quando eu parti." (AKERMAN, 1974) —, relatando em seguida seu primeiro, segundo, terceiro (e assim por diante) dia ali - "No primeiro dia, eu pintei a mobília de azul. No segundo dia, eu pintei de verde. No terceiro dia, eu coloquei tudo na sala." (AKERMAN, 1974). Continua sua perambulação errante ao dirigir-se à estrada para tentar conseguir carona, e parece não a encerrar quando passa a noite em casa da amante, posto que quando deixa o quarto não vemos para onde vai ou o que acontece: sabemos apenas que parte, e não pela primeira vez.

O deslugar está aí, no desconforto que impede Akerman/Julie de permanecer, de pertencer. Um desconforto que não é da ordem do físico, do espacial, mas sim de natureza psíquica: da mente que faz de qualquer casa sua um não-lugar, ao passo que não-lugares como o bar, a estrada e a casa do outro prometem ilusória acolhida. A mudança da cor do 
cômodo e da posição dos móveis na diegese fílmica, bem como a mudança de país na realidade da vida da diretora, expressa a tentativa de conciliar no exterior o que não se encaixa no interior, o que vai ao encontro do que se entende como o cinema que configura e apresenta o deslugar ${ }^{8}$.

Neste sentido, até mesmo as tentativas de relações amorosas são sintomáticas: a personagem experimenta ficar sozinha, mas não suporta; envolve-se fortuitamente com um homem, mas não se mostra satisfeita; finalmente, relaciona-se com uma mulher com que parece estabelecer alguma conexão, mas a quem acaba por abandonar ${ }^{9}$. Não se acomoda aos espaços, não se liga às pessoas, não se mostra confortável nem no corpo que habita. Se desconhece e não reconhece mais o que já lhe foi familiar.

Esteticamente, a suspensão resultante da situação de deslugar em que se encontra Julie é expressa pela duração prolongada das cenas, pela imobilidade da câmera, bem como pelos planos sempre abertos que exibem, disposto na cena, o corpo solto, como que flutuando no espaço e no tempo; os cenários e a direção de arte minimalistas reforçam a sugestão de desamparo: os poucos e esparsos objetos, dispersos por entre paredes nuas, apontam para um esvaziamento que condiz com a situação psicológica da personagem. Fotograficamente, indefinições em preto e branco, por sua vez, oscilando em sombras de claro-escuro, inscrevem na diegese a ambiguidade e a falta de nitidez características do deslugar - o ser sem ser, o estar sem estar.

\section{News from home}

Cenas de longa duração exibindo a cidade de Nova Iorque no final da década de 1970 preenchem os 88 minutos do documentário News from home. Vemos ruas ora vazias, ora ocupadas por transeuntes em seus próprios ritmos e caminhos; há crianças brincando no meio da rua, homens e mulheres inertes, estaqueados em frente a mercearias e bancas de jornal ou em esquinas quaisquer; por vezes, carros surgem estacionados, sem que se veja uma viva alma por perto, em contraponto a momentos em que veículos em movimento

\footnotetext{
8 Isso porque tal condição “[...] se volta, simultaneamente, para o interior e para o exterior, revestido de um caráter marcado pela afirmação e/ou reconfiguração de valores que permeiam as camadas da intimidade e da interioridade, tanto no âmbito do social quanto naquilo que tange à esfera do pessoal/individual. Paradoxalmente, articula-se entre interioridades que, por vezes, revelam-se como espaços de devassamento e exterioridades que se mostram, eventualmente, acolhedoras e aconchegantes." (FISCHER, 2014, p. 160).

9 A relação homoafetiva no filme pode ser considerada elemento de autorreferência, uma vez que Chantal Akerman foi, assumidamente, homossexual.
} 
preenchem o quadro; ora estamos na estação de metrô, contemplando a entrada e saída de passageiros, ora estamos dentro do vagão que percorre sua rota, lançando um olhar demorado e estático sobre as pessoas que estão ali brevemente, bem como sobre o que é revelado do lado de fora das janelas. Pessoas e veículos, dia e noite, vêm e vão sem obedecer a qualquer princípio de linearidade ou causalidade.

Sobre a profusão de imagens da cidade estadunidense, a voz de Akerman, em tom afável e ritmo moderado, narra as palavras de outra pessoa: são cartas da mãe da cineasta, Natalia Akerman, enviadas no período em que a filha viveu nos Estados Unidos. Partindo de Bruxelas, na Bélgica, em novembro de 1971, aos 21 anos, ela ali permaneceu até 1973. Segundo o próprio relato em I don't belong anywhere (LAMBERT, 2015), Akerman tirou seu sustento de trabalhos provisórios, como a bilheteria de um cinema ou a cozinha de um restaurante. As palavras que profere se ocupam do cotidiano de sua família em sua terra natal. A mãe, preocupada, lança uma série de perguntas sobre o trabalho, a moradia, o bemestar da filha, por vezes enviando algum dinheiro para ajudá-la ou roupas para o verão. $\mathrm{Na}$ maior parte do tempo, discorre sobre sua saúde, a do marido e a da filha caçula, as notas escolares desta, os problemas financeiros e a situação dos negócios da família, as novidades dos parentes e amigos. Demonstra-se apreensiva e exausta, frustrada e saudosa; relata que seus únicos momentos de felicidade consistem naqueles em que recebe cartas de Akerman.

Alguns trechos das cartas narradas nos dão indicações de que Akerman possivelmente está na condição de deslugar. Aos três minutos, a primeira delas diz: "Espero que você não fique longe por muito tempo e que tenha encontrado um novo emprego." (AKERMAN, 1976). Com 28 minutos, a mãe comenta: "Fico feliz que não tenha mais aquele emprego [...]" (AKERMAN, 1976). Na mesma carta, continua: "Espero que seu novo flat seja acessível e não esteja em uma área perigosa [...]" (AKERMAN, 1976). Mais tarde, aos 46 minutos, fala: "Você mencionou um emprego diferente. Espero que seja interessante e não muito cansativo." (AKERMAN, 1976). Sabemos que a passagem de poucos minutos entre cada carta citada representa um intervalo de meses ou mesmo um ano, pois entre elas há a referência a dois aniversários de sua irmã mais nova. Portanto, fica subentendido que Akerman não criou raízes em qualquer apartamento ou emprego que teve nesse curto período. Além disso, mais tarde a mãe observa: "Você nunca escreve como realmente vai. Como está seu emprego? Você tem amigos aí? Seu pai acha que você é solitária." (AKERMAN, 1976). A fala parece colocar em dúvida cartas anteriores de Akerman que diziam que estava bem, feliz e gostando de Nova Iorque. 
Por fim, a interlocutora constantemente pergunta quando a filha irá para Bruxelas novamente, mas fica claro que não tem respostas quando diz "Você não disse se está planejando ficar em Nova Iorque [...]" (AKERMAN, 1976), assim como quando relata que o tio de Akerman, que a visitou na cidade e, mais tarde, ligou para Natalia, não mencionou qualquer coisa sobre a volta da jovem. Essa falta de respostas parece apontar para uma incerteza: será que ela mesma sabia se queria ficar em Nova Iorque ou voltar para Bruxelas? Afinal, por mais que estivesse levando a vida ali, o nome que deu ao próprio documentário mostra que não considerava a cidade americana seu lar, mas sim aquela de onde vinham as notícias. Segundo uma das cartas, o pai de Akerman até mesmo queria construir uma casa, em Bruxelas, com um andar separado para que ela vivesse; enquanto isso, a jovem nem mesmo fixou residência em um lugar só em Nova Iorque - em I don't belong anywhere, ao comentar o período em que viveu nesta cidade, a cineasta diz "Não vou contar quantas vezes me mudei, com minhas pequenas sacolas de papel, com todas as minhas coisas [...]" (LAMBERT, 2015).

Forte indicação da condição de deslugar são também as próprias imagens. Fala-se de casa, de amigos e de emprego, mas nunca vemos o lugar onde Akerman mora e trabalha, tampouco ela, mesmo que por trás da câmera, se relacionando com alguém. Pelo contrário, todo o documentário se passa em não-lugares - espaços de transição onde não se estabelecem relações se não superficiais, como a rua, veículos, locais de espera. 0 deslocamento constante, tão caro à definição de deslugar, é verificado aqui não só pelo movimento das pessoas e veículos, mas pela perambulação da própria cineasta, que a cada cena está em um novo espaço - perambula porque busca seu lugar. Além das tomadas em que está dentro do metrô em deslocamento, duas cenas específicas colocam a questão em evidência: uma delas é quando, pela primeira vez, a câmera sai do tripé e é colocada na janela de um carro em movimento para um plano sequência de cerca de 11 minutos; neste momento, a narração das cartas é suspensa. A segunda cena é, também, a última do filme: são mais 10 minutos de plano sequência, agora sobre a água; acompanhamos a câmera saindo de um cais para se distanciar aos poucos, em um barco, da cidade de Nova Iorque, até que seus prédios se tornem uma silhueta; a narração de uma última carta é interrompida na metade, deixando-a sem conclusão. Temos, aí, a impressão de que Akerman se despede da cidade e parte para um novo destino; a interrupção da leitura da carta dá a entender que elas deixam de ser trocadas, pois agora ela foi para casa. No entanto, sabemos que a cineasta também não fica permanentemente lá, em Bruxelas, pois essas cenas foram gravadas em 
1976, quando ela já havia retornado para Nova Iorque - como a própria artista conta no documentário I don't belong anywhere (LAMBERT, 2015), foi dentro do avião de volta para a cidade americana que ela teve a ideia do filme. Teria, então, a casa de onde vêm as notícias deixado de ser seu lar quando a cineasta chegou lá?

Corroborando com a hipótese aqui levantada, é notável o efeito de sentido resultante da fusão entre a paisagem sonora e a narração: ao mesmo tempo em que a afetividade do texto se perde em meio aos sons mecânicos de Nova Iorque, a cidade grande, sempre tão impessoal, ganha um tom mais íntimo e humanizado diante das palavras de carinho de uma mãe. Assim, ambos os lugares — cidade e casa - invertem papéis sem, no entanto, serem destituídos de suas características originais. Não são nem uma coisa, nem outra, porque a cidade natal não deixa de sê-la, mas já não é mais tão acolhedora, e a nova cidade continua não sendo lar, mas acolhe. Essa mesma dualidade inerente ao sentimento de deslugar é verificada, ainda, na oposição entre a dinâmica interior ao plano e a fixidez da maior parte dos enquadramentos, pois o não pertencer a lugar algum que ali se verifica não deixa de ser, em certa extensão, estar em movimento na busca por alguma modalidade de pertencimento e, no entanto, permanecer psicologicamente em estagnação, ou vice-versa (a exemplo de Julie em $\mathrm{Je}, \mathrm{tu}, \mathrm{il}$, elle). As cenas de longa duração apontam para uma suspensão; especialmente nos dois planos sequência abordados há pouco, temos a sensação de que a personagem/cineasta flutua - no tempo, no espaço, na própria interioridade.

Elemento de autorreferência mais evidente e, talvez, mais relevante na obra é a relação maternal: em I don't belong anywhere (2015), Akerman declara que a mãe era constantemente o centro de suas obras, e em No home movie fica evidente a intimidade entre elas. A migração também se faz denominador comum, uma vez que a cineasta de fato saiu de sua cidade por volta dos 20 anos para seguir carreira. Ademais, a escolha das paisagens nova-iorquinas também parece estar sugestivamente associada à subjetividade, considerando-se que as ruas que têm lugar na diegese fílmica são aquelas pelas quais a jovem costumava transitar.

\section{Les rendez-vous d'Anna}

Em Les rendez-vous d'Anna, a protagonista Anna Silver (Aurore Clément) é uma cineasta que viaja sozinha divulgando seu filme mais recente pelo Oeste Europeu. A película 
inicia na Alemanha Ocidental e acompanha seu retorno para casa, passando pela Bélgica até chegar à França. Na primeira cena, vemos sua chegada à estação de trem em Colônia. A câmera fixa, centralizada, registra o momento em que o vazio do local é rompido pelo desembarque dos passageiros; Anna se separa da multidão para ir ao telefone público, fazendo a primeira das diversas ligações que virão no decorrer dos 127 minutos de filme.

Ao chegar ao quarto do hotel em que tem reserva, ela tenta fazer uma ligação para a Itália e fica sabendo que terá de esperar duas horas, por conta do fuso horário. Passa longo tempo deitada em uma das duas camas, liga o rádio, e ali permanece fitando o teto. Mais tarde, ao explorar o quarto - sem, no entanto, se acomodar - encontra uma gravata deixada no roupeiro e liga para a recepção informando sobre a peça esquecida, apenas para descobrir que ela não pertencia ao hóspede anterior. Transcorrido menos de um minuto, liga novamente para a recepção, pedindo para que transfiram a ligação para alguém que mora ali em Colônia. Ao conversar com a interlocutora, primeiro diz que não pode encontrála, pois está ocupada esperando por um telefonema importante, e depois avisa que partirá na noite do dia seguinte (AKERMAN, 1978).

Retornando ao hotel após seu compromisso, Anna o faz acompanhada de Heinrich, um homem que acaba de conhecer, como descobrimos logo em seguida na cena em que a personagem interrompe as preliminares de uma relação sexual apontando que o problema é o fato de eles não se amarem. 0 homem, desapontado, pergunta se as coisas são sempre assim; ela explica "Eu frequentemente deixo alguém ir à minha casa, mas não digo 'vista-se'. Eu deixo acontecer." (AKERMAN, 1978). Ao se despedir, marca um encontro com ele no dia seguinte, às 12 horas. Minutos depois, o telefone entra em cena outra vez, agora para avisála, já ao meio-dia, que Heinrich está à espera; chegando à recepção, é avisada de que perdera duas ligações, uma de sua mãe, outra de um homem. Parte, enfim, para seu primeiro encontro. Como acontecerá em todos os demais, ouve o outro proferir praticamente um monólogo, interrompido apenas por suas respostas monossilábicas.

Mais tarde, na estação de trem, a cineasta tenta novamente ligar para a Itália e não tem sucesso. Em seguida, tem um segundo encontro, desta vez com Ida, para quem havia telefonado na noite anterior. A mulher começa a falar incessantemente, enquanto Anna escuta com paciência, sempre respondendo com poucas palavras; interrompe a conversa para dizer que precisa telefonar a alguém na Itália.

Dentro do trem acontece seu terceiro encontro, quando outro passageiro pergunta se a protagonista está indo a Paris. Durante o diálogo entre os dois, descobrimos que Anna 
viveu vinte anos em Bruxelas, e partiu de lá há oito. 0 homem passa, então, a discorrer sobre os lugares por onde passou e viveu, e compartilha suas perspectivas de um futuro em Paris.

Chegando a Bruxelas, Anna encontra a mãe. Abraçam-se, longa e silenciosamente. É o quarto encontro. Sentam-se em um café, conversam sobre as novidades - pergunta da família, dos negócios dos pais; e conta sobre a própria carreira. Em lugar de ir para casa, ambas decidem passar a noite em um hotel. Lá, a mãe se põe a observar a filha: "Deixe-me apenas olhar para você. Quanto tempo faz?" (AKERMAN, 1978). Anna lembra que não se veem há quase três anos e, em seguida, revela à mãe sua paixão por uma mulher.

Após despedir-se da mãe, a protagonista toma o trem e finalmente chega a Paris, onde então encontra Daniel, seu amante. É o quinto e último encontro. Dirigem a esmo pela cidade conversando sobre suas vidas, até que resolvem passar a noite juntos em um hotel. Lá chegando, não conseguem manter relações sexuais por conta de um mal-estar que acomete o homem. Anna toma um táxi para providenciar medicamento; enquanto a personagem chora, acompanhamos sua demorada trajetória pela cidade mergulhada em silêncio absoluto. Retornando ao hotel, ela cuida de Daniel e depois segue para casa. Uma vez em seu apartamento, deita-se na cama e, imóvel, confere os recados deixados na secretária eletrônica. Ouvimos a gravação de sua voz anunciando que viajará por três dias e deverá retornar na noite de quarta-feira. Em seguida, diversas vozes de pessoas que tentam contato para marcar encontros com Anna (sabemos, agora, frustrados por sua ausência estendida), bem como de alguém, que soa como seu agente, informando suas próximas viagens nos dias que se aproximam.

A inscrição de Akerman em Anna é evidenciada pela profissão e cidade natal que ambas compartilham. 0 elemento de autorreferência mais relevante, no entanto, reside na relação materna. Em I don't belong anywhere (LAMBERT, 2015), Akerman declara que a mãe era constantemente o centro de suas obras, e em No home movie fica evidente a intimidade entre elas; em Les rendez-vous d'Anna, a protagonista ouve, paciente e quase silenciosamente, longas divagações, desabafos e tagarelices em todos os seus encontros; mas é com a mãe, e somente com ela, que encontra ocasião de falar também. Na estação de trem em Colônia, quando Ida pergunta se Anna tem escrito a sua mãe, ela responde: "Sim. As cartas dela são sempre a mesma coisa, e respondo que está tudo bem." (AKERMAN, 1978). A interlocutora relata, então, que soube que a mãe de Anna andava muito cansada, sofrendo com dores na coluna - sabemos, por News from home, que de fato Natalia Akerman se sentia assim constantemente. Este mesmo filme, aliás, nos dá outras indicações relevantes: Natalia 
diz em uma de suas cartas que a família deverá encerrar as atividades da loja na cidade de Tournai e menciona, frequentemente, que os negócios não vão bem; relata, ainda, que a saúde do pai de Akerman também anda frágil, bem como seu ânimo. Em Lez rendez-vous d'Anna, a personagem pergunta à mãe como vão os negócios, e ouve em troca que as coisas vão mal em razão da crise, de modo que seu pai frequentemente demonstra-se infeliz (AKERMAN, 1978).

Após as reclamações, em suas cartas Natalia sempre afirmava consolar-se quando pensava que Akerman estava bem; a mãe de Anna, no filme, diz o mesmo após seu desabafo. Ademais, a cineasta passou três anos sem ver a família quando se mudou de Bruxelas para Nova Iorque, ao passo em que, pelo diálogo no quarto do hotel, descobrimos que Anna e a mãe também ficaram distantes pelo mesmo período.

Em I don't belong anywhere, notamos que Chantal Akerman passou grande (se não a maior) parte de sua vida transitando por diversos países; entre várias estadias breves e outras que duraram alguns anos, teve muitos lares diferentes e passou longo tempo em quartos de hotéis. Anna é um reflexo disso: no filme, passa pela Alemanha, Bélgica e França - e, apesar de o filme não acompanhar esses momentos, sabemos pela mensagem de seu agente que, em breve, ela irá também para duas cidades suíças e uma italiana. Hospeda-se em hotéis nos lugares por onde passa, apesar de em Bruxelas dispor da casa materna - onde também já vivera - e de manter seu próprio apartamento em Paris. A opção de trocar o lar por um não-lugar qualquer, deve-se, parece, a um provável sentimento de deslugar. A casa da família já não é mais lar, mas o apartamento próprio também não acolhe: é mero lugar de passagem, tanto quanto as dependências de hotéis - nas quais, cabe ressaltar, também demonstra desconforto: não se acomoda, não desfaz as malas, não descansa. Fica ainda mais evidente que a personagem não tem uma casa, de fato, quando Heinrich revela que vive na mesma residência desde que nasceu - mais do que isso, cria sua filha ali e afirma ser muito feliz no lugar. Coincidentemente ou não, Anna não é capaz de se conectar com este homem; por outro lado, demonstra ter intimidade com Daniel, que, aparentemente, compartilha de sua situação. A julgar por suas divagações escapistas, mas que sempre terminam com um contraditório conformismo, o homem também se vê deslocado e dividido, como indica o diálogo que mantém com Anna enquanto vagueiam por Paris: “Não há nada na minha casa. E não posso suportar a minha casa. Estou pensando em me mudar." (AKERMAN, 1978). Pouco depois, vai para um hotel com a protagonista. 
Outro sintoma da condição deslugarada aqui proposta é a constante movimentação de deslocamento. Anna passa boa parte do filme dentro de veículos em trânsito - trem, carro de Daniel, táxi - e, conforme notamos em News from home, bem como no documentário de Lambert, o mesmo acontece com Akerman. No filme, no entanto, a protagonista não é a única a experimentar mobilidade constante, impulsionada pela inadequação: há algo do nomadismo em todas as esferas da diegese. 0 homem que Anna conhece em Colônia conta que a mulher abandonou a ele e à filha, partindo com um turco para Frankfurt; bem como revela que seu único colega de trabalho e amigo, Hans, deixara a Alemanha. No encontro com Ida, na estação, o diálogo entre as duas revela que a mulher saiu da Alemanha para viver na Bélgica por 25 anos, mas não se habituou; retornando a seu país, entretanto, já não se sente mais em casa ali também, pois todos os seus amigos ficaram na Bélgica. Sua nacionalidade fica incerta para nós quando Anna pergunta "Você fala alemão tão bem assim? Pensei que fosse polonesa." (AKERMAN, 1978). Temos indicação, também, de que a própria mãe de Anna é imigrante e não se adaptara completamente a Bruxelas quando a filha diz "Mamãe, você tem estado na Bélgica há tanto tempo, e ainda tem sotaque." (AKERMAN, 1978). Cumpre notar, no que diz respeito à adoção de procedimentos autorreferenciais, que a mãe de Akerman mudou-se da Polônia para a Bélgica.

Os telefonemas recorrentes - e frequentemente frustrados - indicam, também, um estar sem estar, pois onde quer que Anna se encontrasse, fisicamente, não era onde se encontrava seu pensamento. Esse desejo de se conectar com o distante e inalcançável, em detrimento ao que estava perto, mesmo diante de si, revela um descontentamento que existe e resiste independentemente das circunstâncias. A protagonista busca, durante o filme todo, contato com a amante italiana, ao mesmo tempo em que é incapaz de se relacionar com o homem alemão e com Daniel - os quais, declaradamente, desejavam-na. Tal como em $J e, t u$, il, elle, a persona de Akerman não só é incapaz de estabelecer pertença, fixação a um lugar determinado, mas também de ligar-se a outrem (e a si mesma, bem olhado). Quando busca no outro o bálsamo de algum refúgio ou atenuante que minore a angústia de que é presa, tudo o que consegue é evidenciar quão desabridamente não está e nem nunca esteve confortável na própria pele.

Imageticamente, o sentimento de estar ali desejando estar lá, e chegar lá sem o querer mais - seja onde for o ali e o lá - é traduzido na frequência das cenas que exibem a contemplação através das janelas - do hotel, do trem, do táxi -, o olhar da personagem sempre voltado para o além. Assim como nos outros dois filmes, a câmera fixada no centro 
do espaço filmado também nos traz algo de inadequação, como se tudo ao redor estivesse no lugar apropriado e a figura da personagem, no centro de tudo isso, surgisse flagrantemente deslocada. Os elementos talvez mais explicitamente atrelados ao deslugar, no entanto, nos parecem ser as inscrições que se destacam: quando Anna chega à estação de Colônia, a câmera centraliza as escadas acima das quais está escrito "ausgang", palavra alemã para saída. Observamos o mesmo quando chega e cruza a porta do hotel, na mesma cidade, bem como no hotel de Paris. Está aí representada a ambiguidade do conceito: a personagem está sempre chegando para partir, nunca para ficar. Porque onde quer que esteja, qualquer outro lugar se lhe afigura - ilusoriamente - melhor.

\section{Considerações finais}

O cotidiano é fio condutor do cinema de Chantal Akerman; ela mesma ressalta, em entrevista a Lambert no documentário I don't belong anywhere (2015), que seus filmes são preenchidos pela repetição, pela obsessão, pelo confinamento, pelos corredores, pela cozinha, bem como pelas imagens de quartos, saguões e veículos, como pudemos observar. É na camada invisível do rotineiro, na monotonia reiterada da vivência de cada dia que se manifesta o deslugar. Justamente nesses cenários e nessas situações pouco ou nada extraordinários se revela, afinal, a atrofia das articulações de relações sociais viciadas ou deficientes, em que a intimidade dá lugar ao estranhamento, ao distanciamento. Nos filmes aqui em tela, o cotidiano está em desordem, nada está em seu devido lugar. A casa de Julie não traz conforto, mas não é possível permanecer indefinidamente no caminhão do desconhecido ou na casa da amante (espaços que, de resto, muito pouco se lhe afiguram acolhedores); a cidade de Nova Iorque não é lar, tampouco o é a casa da família em Bruxelas. As personagens, ainda que rodeadas por outras pessoas, conhecidas ou estranhas, revelamse em plena solitude. Não porque assumidamente evitam ou não procuram elos e enlaces, mas sim porque não conseguem estabelecer conexões.

As películas que compõem o corpus desta pesquisa trazem três modos da presença de Chantal Akerman: ela mesma, fisicamente presente, como atriz (Je, tu, il, elle), ela mesma, fisicamente não vista, por meio da narração e dos fragmentos de sua vida íntima expostos nas cartas da mãe (News from home) e, por fim, indícios dela mesma em uma personagem interpretada por outra atriz (Les rendez-vous d'Anna). Nos dois primeiros casos, as cartas 
parecem desempenhar a função de inscrever na tela sua própria vivência, íntima e histórica, enquanto os telefonemas e encontros desempenham essa função no último filme. Seria isso suficiente, então, para afirmar que a cineasta estaria em deslugar tanto quanto suas personagens? Evidente que não. É pouco. I don't belong anywhere, no entanto, nos permite ousar fazê-lo. Nele, destacam-se dois fragmentos que, somados às reflexões sobre os outros dois filmes, parece nos dar por solucionada a questão. 0 primeiro é quando Lambert repete a cena final de News from home, sobre um barco em movimento, com o skyline de Nova Iorque ao fundo. Desta vez, Akerman diante das câmeras, e ao lado dela duas outras pessoas, às quais informa, durante uma conversa: "Estou vivendo entre aqui [Nova Iorque], Paris, Bruxelas, Israel. Eu sou uma pessoa nômade." (LAMBERT, 2015). 0 segundo momento é a última cena do documentário. Nela, Akerman está no centro da tela, trilhando uma estrada deserta, rodeada por nada além de terra e mais terra. Não vemos o fim da estrada, que se perde no horizonte e some no quadro. A cineasta segue caminhando, vagarosamente. Para onde? Mais uma vez, não se sabe.

Há evidências que remetem diretamente à pessoa Chantal Akerman (tal como ela se dá a ver em seu estar no mundo) em suas películas e personagens; entende-se, assim, que tais traços possivelmente indicam condição de deslugar na inteligência criadora dos filmes. Partindo dessas premissas, pode-se afirmar que as obras em questão se fazem ato de tal teoria? Acredita-se, após a reflexão proposta, que a resposta para o questionamento norteador da presente pesquisa tende a ser positiva: se a inteligência criadora que se expõe na criação encontra-se em tal condição, então esta se faz sensível nas películas, de modo que elas são capazes de tornar o enunciado linguístico da ideia em questão em enunciado imagético. Arranca-se, aí, a teoria do universo abstrato para concretizá-la, torná-la esteticamente palpável e inteligível. Faz-se da teoria de deslugar um ato.

Cabe notar, por fim, que Akerman não declarou ter tido intenção de demonstrar ou teorizar sobre, por meio de indícios do eu (do si mesmo) em seus filmes, o deslocamento psicológico-afetivo que possivelmente experimentou durante a vida. Tal condição de deslugar, do modo como foi aqui explicitada, é - enfatize-se novamente - uma noção que se acha em estágio de desenvolvimento e, nessa perspectiva, encontrou em filmes como os de Akerman uma forma peculiar, particularmente interessante, de representação ${ }^{10}$. Igualmente

\footnotetext{
10 Neste sentido, foi intenção do estudo percorrer um caminho que já há muito existe em pesquisas acadêmicas sobre o cinema: encontrar nas criações de cineastas uma unidade teórica que as orientam, sem que necessariamente esta seja de autoria daqueles que idealizam as películas. Basta pensar, por exemplo, no caso da dialética hegeliana verificada em Jacques Rivette.
} 
importante é ressaltar que, dada a natureza hipotética deste estudo e o processo ainda em construção do conceito aqui tratado, as asserções (ou considerações) resultantes da presente investigação revestem-se, por enquanto, de cautelosa provisoriedade.

\title{
Referências
}

AUGÉ, Marc. Não-lugares: introdução a uma antropologia da sobremodernidade. Campinas: Papirus, 2010.

AUMONT, Jacques. Pode um filme ser um ato de teoria? Educação e Realidade, Porto Alegre, v. 33 n. 1, p. 21-34, 2008.

FISCHER, Sandra. Pai e filha, não por acaso: cotidiano, lugar e deslugar. Significação, São Paulo, v. 37, n. 34, p. 141-152, 2010.

FISCHER, Sandra. O palhaço silencioso, melancólico Somewhere, perplexidades: o deslugar no cinema contemporâneo. Rumores, São Paulo, v. 8, n. 15, p. 154-170, 2014.

FOUCAULT, Michel. 0 que é um autor? Lisboa: Nova Vega, 2006.

I DON’T belong anywhere. Direção: Marianne Lambert. Bélgica. Produção: Icarus Films, 2015. 1 DVD (67 min.).

JE, tu, il, elle. Direção: Chantal Akerman. Bélgica, França. Produção: Paradise Films, 1974. 1 DVD (90 min.).

LACAN, Jacques. Escritos. São Paulo: Perspectiva, 1978.

LES rendez-vous d'Anna. Direção: Chantal Akerman. Bélgica, França, Alemanha Ocidental: Produção: Hélène Films, Paradise Films, Unité Trois, Zweites Deutsches Fernsehen (ZDF), 1978. 1 DVD (127 min.).

NEWS from home. Direção: Chantal Akerman. França, Bélgica. Produção: Institut National de l'Audiovisuel (INA), Paradise Films, Unité Trois, Zweites Deutsches Fernsehen (ZDF), 1976. 1 DVD (85 min.).

\section{The self-referential cinema of Chantal Akerman as a theoretical act of displacement}

\author{
Abstract \\ The paper examines the condition of displacement focusing its \\ critical-analytical perspective proprietarily on the universe of the \\ filmmaker, once it is not rare, in post-modernity and
}


contemporaneity, to see elements of the directors' personal lives affecting their productions. This seems to be the case of Chantal Akerman, whose filmography frequently presents indications of herself in both fiction and documentary movies, where it is possible to identify, in what can be understood as displacement, the predominance of a peculiar lack of belonging expressed through constant dissatisfaction and wandering. In this sense, under the light of the reflections of Jacques Aumont concerning the film as a theoretical act, this study stems from the comparative analysis as a method to observe excerpts of $J e$, Tu, il, elle (1974), News from home (1976), and Les rendez-vous d'Anna (1978). Through the analysis, the research relates the self-referential thought that conducts the Belgium director's narratives to the one that sustains the proposal of the concept of displacement. Seeking to confirm the hypothesis that the spatial and psychological dislocation can be considered as a distinctive trait of Akerman's work, the objective of the study is to investigate if and how this characteristic spans her whole oeuvre, impregnating its creating intelligence in such a way that it directly affects the poetic and sensitive articulations. By comparing Akerman's statements on the documentary I don't belong anywhere (2015) with the diegesis of the corpus in question, the outcomes achieved indicate that, for now, it is possible to confirm the manifestation of a condition of displacement both in the characters and their creator.

\section{Keywords}

Chantal Akerman. Displacement. Self-reference. Theoretical act.

Recebido em 28/04/2019

Aceito em 29/07/2019 